\title{
História Oral no Brasil: uma análise da produção recente $(1998 / 2008)^{*}$
}

\author{
André de Faria Pereira Neto** \\ Bárbara Araújo Machado*** \\ Antonio Torres Montenegro***
}

\section{Introdução}

O objetivo deste artigo é apresentar uma análise preliminar da produção acadêmica brasileira de História Oral entre 1998 e 2008. Duas fontes servirão de base para nossas reflexões: os artigos publicados na revista da Associação Brasileira de História Oral - História Oral - e os cadernos de resumos das comunicações apresentadas nos encontros nacionais que a mesma associação organizou nos últimos anos.

No primeiro caso foram publicados dez números da revista História Oral desde 1998, sendo que, em 2005 e 2006, quatro números foram lançados. No total, estes números reuniram a produção de 91 autores em seus 86 artigos. Cada número teve um editor responsável, um tema central

* Este trabalho foi apresentado na reunião da Regional Oral History Office (ROHO) Office of The Bancroft Library na Universidade de Berkeley, na Califórnia em 2006 e no XXIV Simpósio Nacional da História organizado pela Associação Nacional de História (ANPUH) realizado em São Leopoldo, Rio Grande do Sul em 2007.

** Pesquisador da Casa de Oswaldo Cruz, Fundação Oswaldo Cruz (FIOCRUZ).

*** Bolsista de Iniciação Científica da Casa de Oswaldo Cruz, Fundação Oswaldo Cruz (FIOCRUZ).

**** Professor do Departamento de História da Universidade Federal de Pernambuco (UFPE). 
e além de artigos e entrevistas. Em relação aos encontros nacionais, quando são produzidos os cadernos de resumos ${ }^{1}$ configura-se o seguinte quadro:

\begin{tabular}{|llcc|}
\hline Ano & Local & Resumos & Participantes \\
\hline 1996 & Campinas & 20 & 23 \\
\hline 1997 & Recife & 62 & 72 \\
\hline 1999 & Belo Horizonte & 111 & 137 \\
\hline 2002 & São Paulo & 198 & 242 \\
\hline 2004 & Goiânia & 165 & 219 \\
\hline 2006 & Rio Branco & 123 & 141 \\
\hline 2008 & São Leopoldo & 339 & 384 \\
\hline TOTAL & & $\mathbf{1 . 0 1 8}$ & $\mathbf{1 . 2 1 8}$ \\
\hline
\end{tabular}

Este artigo está dividido em duas partes. Na primeira desenvolveremos uma breve análise histórica e historiográfica do contexto em que emergiu a História Oral no Brasil. Neste caso faremos alusão ao momento em que essa técnica e essa metodologia (história oral) tornou-se alvo de um uso mais sistemático e efetivo - principalmente - dos historiadores suscitando, por conseguinte, um amplo debate teórico. Além disso, apresentaremos em linhas gerais a história da criação da Associação Brasileira de História Oral (ABHO). Na segunda parte apresentaremos os resultados de nossa pesquisa sobre a produção acadêmica brasileira de História Oral, ressaltando o perfil dos autores e dos temas abordados.

1 Não tivemos condições de obter informações sobre os dois primeiros encontros nacionais de história oral, realizados respectivamente em São Paulo (1993) e Rio de Janeiro(1994). 


\section{Momento histórico e historiográfico}

O uso da técnica e da metodologia da história oral de maneira mais efetiva e acadêmica no Brasil, pela comunidade dos historiadores, coincide com um momento político singular de nossa história política: o fim do regime militar e o incremento das lutas por liberdade de imprensa, pela anistia e pelo exercício pleno dos direitos do cidadão. No final dos anos 1970 iniciou-se no país uma ampla campanha pela anistia que tinha como finalidade restabelecer o Estado de Direito assegurando as liberdades civis. Em termos historiográficos, muitos cientistas sociais brasileiros viviam um momento em que buscavam outras formas de tratar e analisar seus objetos de investigação que não se aproximasse do estruturalismo, do historicismo e dos métodos quantitativos. Ao mesmo tempo, ampliava-se a influência de historiadores que remetiam a problemática da microhistória, não se satisfazendo apenas com as grandes explicações macrohistóricas. Desse modo, ocorreram em 1975 as primeiras experiências sistemáticas no campo da História Oral no país: especialistas norte-americanos e mexicanos ministraram cursos no Centro de Pesquisa e Documentação da Fundação Getúlio Vargas, no Rio de Janeiro, com o patrocínio da Fundação Ford. A partir de então a História Oral foi ganhando adeptos através de um processo lento e descontínuo.

Naquele período houve um crescimento do número de pesquisadores que passaram a utilizar esta metodologia. Entretanto, naquele contexto, as fontes orais eram utilizadas, sobretudo, como complementares aos documentos escritos. Além disso, poucos cursos de graduação e de pósgraduação em História incluíam essa metodologia como disciplina a ser ofertada aos estudantes. A objetividade supostamente presente no documento escrito era um dos argumentos utilizados para afirmar a completa impossibilidade do historiador fazer uso do depoimento ou entrevista oral já que este, fundado na memória, se caracterizaria pela sua dimensão subjetiva e, por conseguinte irreal. Além disso, a denominada "História do Tempo Presente" era vista com desconfiança por parte de uma parcela da comunidade de historiadores, que defendia a necessidade de um distanciamento temporal entre o pesquisador e o objeto estudado. A imparcialidade fundada no distanciamento temporal (entre o pesquisador e o período ou acontecimento em estudo) era considerada um dos critérios fundamentais da verdade científica. Assim, até a década de 1990, 
"a história oral não merecia figurar nos currículos dos cursos universitários, implicava pouca reflexão e não constava na programação de seminários e simpósios" (Ferreira, 1998, p. 20).

No início dos anos 1990, a crítica ao predomínio do documento escrito como fonte exclusiva para o historiador foi acompanhada pelo impulso da História Cultural, da História do Cotidiano e da História das Mentalidades. Essas novas correntes historiográficas, em estreito diálogo com a Antropologia Cultural, promoveram a ampla utilização de fontes que privilegiavam dimensões qualitativas das experiências históricas, bem como a incorporação das vivências individuais na escrita da história. Dessa maneira, o depoimento oral passou a ocupar lugar central em muitos trabalhos acadêmicos. Segundo Ferreira, as mudanças historiográficas com sua contrapartida nas transformações na própria sociedade, a partir dos anos 1990 produziram também um crescente interesse pelo tema da memória coletiva e individual promovendo "um verdadeiro boom da história oral" (Idem, p. 22).

\section{Questões e controvérsias}

A História da História Oral no Brasil foi acompanhada por algumas questões e controvérsias que de certa forma já vinham sendo debatidas nos fóruns internacionais, principalmente entre pesquisadores que se reuniam na International Oral History Association.

Uma delas refere-se ao valor e à função do depoimento oral. Existiram e existem autores que defendem a idéia de que ele deve servir, sobretudo, para preencher as lacunas deixadas pela documentação escrita. Por esta razão, as informações contidas nos depoimentos orais devem ser objetivas e comprováveis. Nesse sentido, há uma preocupação com a formulação de um detalhado roteiro de entrevista e com a utilização de fontes escritas "para realizar a contraprova e excluir distorções" (Ferreira, 1994, p. 9). Poder-se-ia afirmar que os historiadores que trabalham nessa perspectiva recorrem a uma das dimensões mais pobres da memória, que é o de simples registro ou informação positiva acerca de um fato ou acontecimento. Ao mesmo tempo estes historiadores desconsideram ou descartam a dimensão da elaboração do trabalho onde se desvela uma mistura de temporalidades. Nesta oportunidade as experiências do presente 
estabelecem diversos níveis de interação com o passado e com a memória. Neste contexto o passado da memória é adquire um outro significado e ao mesmo tempo provoca deslocamentos na percepção e na compreensão do presente (Montenegro, 2008).

Seguindo um outro caminho, alguns autores insistem em valorizar o papel atribuído às relações entre memória e história e o estudo das representações. Autores que utilizam essa abordagem não buscam uma verdade nos fatos, mas vêem a subjetividade do depoimento oral como mais um desafio à pesquisa, e não um problema. O estudo de elites políticas, por exemplo, tem se desenvolvido muitas vezes enfatizando o imaginário político, enquanto que em alguns estudos das camadas populares há uma preocupação com os problemas relativos ao conceito de representação.

Outra discussão metodológica que acompanhou a produção acadêmica brasileira em história oral relaciona-se com a maneira com que deve ser feita a crítica histórica ao depoimento oral. Esta crítica histórica torna-se ainda mais complexa pelo fato do depoimento oral ser construído (Joutard, 1983) com o entrevistador. Assim questiona-se em que medida a relação entre o entrevistador e o entrevistado afeta o conteúdo do depoimento e sua posterior análise. Grele argumenta que, como a história oral coleta depoimentos subjetivos, é necessário "olhar para a entrevista como um texto" (Grele, 2005, p. 84), investigando os níveis ocultos de discurso na narrativa.

Além disso, os autores discutem até que ponto o depoimento de uma única pessoa tem condições de ser generalizado ou deve ser visto como uma singularidade desvinculada do contexto sociocultural em que o depoente está inscrito. Aspásia Camargo, em entrevista prestada a Maria Celina d'Araújo argumenta, por exemplo, que "a entrevista era uma forma de apropriação de um processo mais amplo, que o ator consegue transmitir, porque, junto com ele, trazia toda sua vivência" (D’Araújo, 1999, p. 171). No entanto, não se pode desconhecer que em toda entrevista, mesmo aquela que relata memórias de experiências bastante singulares, a dimensão social é constitutiva desta em razão dos aspectos lingüísticos, culturais, econômicos ou mais propriamente históricos formadores de qualquer indivíduo. Logo, o historiador tem diante de si um documento que é individual e social ao mesmo tempo. Cabe a ele construir itinerários teóricos e analíticos que operem adequadamente com a 
multiplicidade de níveis de realidade e de temporalidade que essa fonte apresenta (Montenegro, 2006).

Por outro lado, a utilização do depoimento, no cruzamento com outras fontes, aumenta o grau de complexidade da análise histórica. O relato oral de memória, ao se constituir como reconstrução ou releitura (de marcas, experiências, imagens, acontecimentos), a partir do presente, possibilita muitas vezes estudar como o passado adquire novas significações. As experiências sociais, políticas, culturais do presente produzem deslocamentos nas pessoas, nos grupos e nas classes sociais e, por extensão, outras formas de significar e compreender a história.

Estas questões permearam o desenvolvimento da História Oral no Brasil e se fazem presentes nos debates promovidos pela $\mathrm{ABHO}$ desde a sua fundação, quer nos encontros regionais, quer nos encontros nacionais. Dessa forma, tem ocorrido um constante debate crítico entre os diversos profissionais que perceberam a necessidade da utilização dessa fonte em suas pesquisas, permitindo que fosse construída uma sólida base de reflexão conceitual e metodológica sobre este campo de conhecimento no Brasil.

Assim desenvolveram-se tanto pesquisas com elites quanto com grupos excluídos. Segundo Ferreira (1994, p. 9), "na recuperação da história dos excluídos, os depoimentos orais podem [...] constituir-se em instrumentos de construção de identidade e de transformação social".

\section{A história da Associação Brasileira de História Oral}

No primeiro encontro de História Oral, realizado em 1992, foi proposta a criação de uma Associação Brasileira de História Oral. No encontro seguinte, realizado na Fundação Getúlio Vargas em 1994, a ABHO foi fundada e a assembléia aprovou seu estatuto que definiu a História Oral como o "trabalho de pesquisa que utiliza fontes orais em diferentes áreas de conhecimento nas quais essa metodologia é utilizada" (Estatuto da ABHO, Parágrafo Único).

Com a criação da Associação Brasileira de História Oral (ABHO) passaram a ser realizados encontros regionais e nacionais que permitiram a integração dos pesquisadores de diversas regiões do país. Os encontros nacionais ocorreram de dois em dois anos, na maioria das vezes, no estado em que se encontrava a presidência da associação. Já os encontros regionais, 
que ocorreram nos intervalos dos encontros nacionais, e foram realizados nos diversos estados das cinco regiões (Norte, Nordeste, Centro-Oeste, Sudeste e Sul) do Brasil. A importância que ganhou o uso das fontes orais na produção do conhecimento de diversas áreas possibilitou que muitos encontros regionais adquirissem dimensões de encontros nacionais, quer pelo grande número de inscritos (entre 500 e 1000 participantes), quer pela diversidade de palestrantes e conferencistas tanto brasileiros como estrangeiros.

A escolha do nome "Associação Brasileira de História Oral"2 residiu na necessidade de sua interlocução e reconhecimento internacionais. Este fato sem dúvida facilitou a representação institucional dos pesquisadores brasileiros que passaram a participar de encontros internacionais. Além disso, muitos pesquisadores dos EUA e da Europa passaram a ser convidados para os encontros de história oral no Brasil. Com isso, os pesquisadores brasileiros passaram a desenvolver um diálogo cada vez mais intenso com pesquisadores de outros países.

Muitos pesquisadores brasileiros tiveram atuação importante na fundação da International Oral History Association (IOHA) - movimento de história oral internacional, liderado por Ronald Grele, Mercedes Vilanova, Alexandro Portelli, Paul Thompson, Luiza Passerini. Depois da criação formal da Associação Internacional de História Oral em 1996, na cidade de Gotemburgo, na Suécia, o Brasil foi escolhido como sede do II $^{\circ}$ Encontro Internacional de História Oral. A escolha do Brasil revela a importância que a produção científica em história oral passou a assumir em nosso país e o diálogo internacional cada vez mais intenso de nossos pesquisadores.

Um outro fator que revela a força e a vitalidade da pesquisa com as fontes orais, bem como da ABHO como representante e locus desse importante debate acadêmico, político e cultural, foi a criação da Revista História Oral, em 1998. Este é atualmente o principal periódico da área, tendo alcançado já há alguns anos na avaliação da CAPES, o nível de revista Nacional A.

$2 \mathrm{Na}$ assembléia de aprovação do estatuto e fundação da $\mathrm{ABHO}$, no $\mathrm{II}^{\circ}$ Encontro Nacional, realizado nas dependências do CPDOC no Rio de Janeiro em 1994, muitos pesquisadores da área de Antropologia, Sociologia e Educação principalmente, não concordavam com a utilização da expressão "História Oral" para nomear esta associação. O argumento que de certa forma selou uma certa concordância foi a questão da interlocução internacional, pois caso a associação não utilizasse a expressão "história oral" seria muito mais difícil sua identificação. Por essa razão o primeiro parágrafo do estatuto afirma que a $\mathrm{ABHO}$ congrega pesquisadores que trabalham com fonte orais, ou seja, nem todos os pesquisadores são obrigados a utilizar a metodologia da história oral para serem associados. 


\section{A produção acadêmica brasileira de História Oral}

Dividimos a produção acadêmica brasileira de História Oral em dois pontos. No primeiro, analisamos o perfil dos autores e, no segundo, os temas mais estudados. No primeiro caso levamos em consideração a origem nacional, regional, profissional e institucional dos autores. No segundo, identificaremos os temas mais presentes nos artigos da Revista História Oral e nas comunicações em congressos. Como será observado a seguir, existe uma vasta produção que contempla questões relativas aos grupos denominados populares ou mesmo analfabetos e aquelas relacionados com as elites, além dos artigos que enfocam predominantemente reflexões de cunho teórico ou metodológico.

\section{Perfil dos autores}

A tabela que se segue apresenta os dados relativos à origem regional dos autores nacionais dos artigos publicados nos dez volumes da Revista História Oral lançados entre 1998 e 2007, e os dados relativos à origem regional dos autores dos trabalhos apresentados nos Encontros Nacionais da ABHO (que tiveram seus resumos publicados nos respectivos anais). Neste caso, não foram incluídas as mesas redondas, conferências e as apresentações de pôster. A finalidade da organização do quadro foi revelar se houve ou não uma concentração geográfica na origem regional dos autores dos artigos e das comunicações nos encontros.

\begin{tabular}{|l|c|r|c|c|}
\hline & \multicolumn{2}{|c|}{$\begin{array}{c}\text { Revista } \\
\text { História Oral }\end{array}$} & \multicolumn{2}{c|}{$\begin{array}{c}\text { Encontros } \\
\text { Nacionais } A B H O\end{array}$} \\
\hline Região & Num. & $\mathbf{\%}$ & Num. & \% \\
\hline Norte & 4 & 4,4 & 58 & 4,8 \\
\hline Nordeste & 11 & 12,1 & 222 & 18,5 \\
\hline Centro-Oeste & 5 & 5,5 & 155 & 12,9 \\
\hline Sul & 10 & 11 & 262 & 21,8 \\
\hline Sudeste & 61 & 67 & 503 & 42 \\
\hline TOTAL & $\mathbf{9 1}$ & $\mathbf{1 0 0}$ & $\mathbf{1 . 2 0 0}$ & $\mathbf{1 0 0}$ \\
\hline
\end{tabular}


É possível perceber em primeiro lugar, em relação à Revista História Oral a presença da contribuição de pesquisadores de todas as regiões do país e ao mesmo tempo uma sensível concentração na região sudeste. Em linhas gerais, esta tendência pode ser percebida tanto na produção bibliográfica quanto na participação nos Encontros Nacionais. Por outro lado, a participação da região Sul nos encontros nacionais foi incrementada, sobretudo depois da realização do último encontro nacional em São Leopoldo. O fato do VII Encontro Nacional ter sido realizado em Goiânia contribuiu para a expansão da História Oral naquela região, que contou com a forte participação do Núcleo de História Oral do Distrito Federal, de Mato Grosso e Mato Grosso do Sul, do Tocantins e mesmo da região Norte.

Os números expressivos representativos da região Sudeste tanto em artigos na Revista História Oral bem como na participação nos Encontros Nacionais se deve ao fato dela concentrar um maior número de instituições universitárias e de pesquisa que utilizam à História Oral.

Todos os autores de artigos em todos os números da Revista História Oral têm uma vinculação universitária enquanto que apenas seiscentos e noventa e três (693) dos mil duzentos (1200) participantes dos Encontros Nacionais trabalham em instituições de nível superior. Cerca de 90\% dos profissionais que publicaram artigos no periódico da ABHO atuam em instituições públicas, mantidas pelos governos Federal ou Estadual e não em instituições particulares. Estes dados permitem concluir que os autores nacionais não se originam dos movimentos sociais ou empresas como ocorre em outros países.

Em relação à formação profissional dos autores dos artigos, assim como dos pesquisadores que participam dos Encontros Nacionais (ver quadro à página seguinte), observa-se que o uso das fontes orais está no cotidiano da pesquisa de pesquisadores de diferentes áreas.

O predomínio de pesquisadores vinculados às universidades, bem como o predomínio de historiadores, são duas tendências marcantes que instituem um perfil diferenciado da história oral no Brasil, em relação aos EUA e a Europa.

Nos últimos anos a $\mathrm{ABHO}$ vem implementando uma política de descentralização da presidência, calcada no fortalecimento dos núcleos regionais. Assim, em 2004 a presidência foi para o estado do Acre, em 2006 para o Rio Grande do Sul e em 2008 retornou a Pernambuco. 


\begin{tabular}{|l|c|c|c|c|}
\hline & \multicolumn{2}{|c|}{$\begin{array}{c}\text { Revista } \\
\text { História Oral }\end{array}$} & \multicolumn{2}{c|}{$\begin{array}{c}\text { Encontros } \\
\text { Nacionais } A B H O\end{array}$} \\
\hline Autor ${ }^{3}$ & Num. & $\mathbf{\%}$ & Num. & $\mathbf{\%}$ \\
\hline Historiador & 58 & 63,7 & 559 & 32 \\
\hline Cientista Soc. & 18 & 19,8 & 126 & 13 \\
\hline Educador & 7 & 7,7 & 139 & 15 \\
\hline Arquivista & 0 & 0 & 3 & 0,4 \\
\hline Bibliiotecário & 0 & 0 & 5 & 0,3 \\
\hline Jornalista & 0 & 0 & 3 & 0,3 \\
\hline Outros & 8 & 8,8 & $362^{4}$ & 39 \\
\hline
\end{tabular}

Cabe ainda um destaque à presença de pesquisadores estrangeiros em diversos números da Revista da Associação Brasileira de História Oral: vinte e cinco dos noventa e dois autores são de diversos outros países. Este número equivale a $27,2 \%$ do total de autores. Poucos periódicos nacionais devem ter um percentual tão acentuado de pesquisadores estrangeiros. Além disso, cabe ressaltar que esta presença pode ser percebida em todos os números, concentrando-se nos autores europeus (14), latinoamericanos (8), norte-americanos (3). Esta participação significativa de pesquisadores internacionais sugere a busca de um diálogo sem fronteiras.

\section{Perfil dos temas}

Os temas dos artigos publicados na Revista História Oral da ABHO e das comunicações nos grupos de trabalho dos Encontros Nacionais da ABHO foram classificados a partir das suas temáticas.

3 Para organizar essa tabela nos baseamos nas informações disponíveis na Plataforma Lattes do CNPq.

4 Entre as diversas outras profissões identificadas, algumas das mais expressivas foram a de psicólogo, comunicólogo, lingüista e assistente social. As profissões que constam na tabela foram destacadas por uma questão de comparação com o desenvolvimento internacional da História Oral, marcado pela presença de arquivistas, bibliotecários, etc. 
No primeiro grupo reunimos artigos e comunicações que analisassem os setores sociais denominados "populares" ou mesmo analfabetos, além de categorias sociais como os trabalhadores fabris e camponeses, além dos povos indígenas. Nos trabalhos de pesquisa voltados para este segmento social encontra-se um interesse significativo pelas manifestações culturais com escasso registro escrito, quer no campo da arte, quer no campo religioso. No segundo grupo reunimos a produção teórica sobre História Oral que inclui trabalhos historiográficos, metodológicos e conceituais. No terceiro grupo reunimos a produção voltada para o segmento social nomeado por "elites" (ou "dominantes"), sejam elas políticas, intelectuais ou profissionais. Neste último caso, muitos trabalhos foram encomendados por empresas ou instituições corporativas (Pereira Neto, 1997).

\begin{tabular}{|l|c|c|c|c|}
\hline & \multicolumn{2}{|c|}{$\begin{array}{c}\text { Revista } \\
\text { História Oral }\end{array}$} & \multicolumn{2}{c|}{$\begin{array}{c}\text { Encontros } \\
\text { Nacionais }\end{array}$} \\
\hline \multicolumn{1}{|c|}{ Tema } & Num. & $\mathbf{~ \% ~}$ & Num. & $\mathbf{\%}$ \\
\hline $\begin{array}{l}\text { Camadas populares e suas } \\
\text { manifestações culturais }\end{array}$ & 42 & 48,8 & 330 & 15 \\
\hline $\begin{array}{l}\text { Historiografia, teoria } \\
\text { e metodologia }\end{array}$ & 31 & 36,1 & 401 & 51 \\
\hline Segmentos dominantes & 13 & 15,1 & 292 & 34 \\
\hline
\end{tabular}

Estes dados merecem uma análise mais detida. Cabe mencionar, por exemplo, que no VI Encontro Nacional, realizado em São Paulo, 116 dos 198 trabalhos abordaram temas teóricos e metodológicos. Apesar de poderem parecer por demais esquemáticos ou reducionistas, estes critérios de classificação oferecem uma amostra do perfil da produção nacional de História Oral.

\section{Considerações finais}

Os dados apresentados ao longo deste artigo podem ser analisados comparativamente ao desenvolvimento da História Oral no plano internacional. 
No caso dos Estados Unidos, por exemplo, o início da História Oral ocorreu em arquivos e bibliotecas, e não em universidades, como no caso brasileiro. Para Grele (2005), este processo se deu porque, a princípio, as fontes orais eram vistas como meio de preencher lacunas de registros escritos. Dessa forma, a história a ser estudada era apenas a dos grupos letrados, sendo, portanto, uma história oral fundamentalmente elitista. Segundo Grele, os movimentos de contestação dos anos 1960 e 1970, juntamente com a nova história social colocaram em voga a história dos grupos excluídos, impulsionando uma nova forma de se fazer História Oral naquele país.

Analisando ainda o caso Norte-Americano, poderíamos mencionar o ponto de vista de Richard Smith (2003), da Universidade da Califórnia. Este autor aponta que a grande popularidade da história oral nos Estados Unidos pode ser notada com a constatação do grande volume de fontes orais arquivadas. Contudo, ele sinaliza que esta grande quantidade não vem sendo analisada pelos pesquisadores. $\mathrm{O}$ número de entrevistas disponíveis estaria além da capacidade de pesquisa, sendo às vezes arquivadas sem terem sido transcritas. Diante desse quadro, o autor identifica a necessidade de desenvolver a capacidade da história oral para "moldar o entendimento do passado" (Smith, 2003, p. 48). Para tal, Smith aponta a importância de conjugar pesquisa, ensino e arquivamento em programas coerentes vinculados a universidades.

Analisando o processo de institucionalização da História Oral na Grã Bretanha, Perks (2003) ressalta o papel de arquivistas e bibliotecários nos primórdios da História Oral, tal como ocorreu nos Estados Unidos. Contudo, no caso britânico a História Oral foi vista pelos arquivistas tradicionais com estranheza, já que documentos deveriam ser produzidos sempre contemporaneamente aos acontecimentos históricos, fixados no passado. Para Perks, a História Oral foi impulsionada na Grã Bretanha pela inexistência de documentos escritos sobre parcelas significativas da sociedade britânica, além do entendimento quanto à importância dos arquivos áudio-visuais para que a sociedade moderna fosse entendida no futuro. O autor ressalta ainda o papel dos museus, das "profissões de cuidado" como o serviço social e das escolas no desenvolvimento da História Oral britânica.

Assim, verificamos diferenças significativas em relação ao processo de desenvolvimento da História Oral no Brasil, marcado a princípio pela 
abertura política de uma ditadura civil-militar e, posteriormente influenciado pela Nova História Cultural. Ainda assim, a preocupação em "dar voz" a grupos excluídos é um ponto em comum entre os países citados, o que se revelou em nossa análise através da maioria de projetos de pesquisa acerca destes grupos.

Este trabalho apresentou um delineamento da história da Associação Brasileira de História Oral e uma análise sobre a produção acadêmica nacional que se reflete na produção acadêmica apresentada nos Encontros Nacionais da ABHO e nos artigos publicados na Revista História Oral. Por meio da trilha histórica apresentada nesse artigo é possível compreender a força que a história do tempo presente adquiriu nas duas últimas décadas no Brasil. E, nesse sentido, este artigo expressa como o trabalho com os relatos orais de memória ganhou um peso significativo na historiografia recente, além de ampliar o diálogo interdisciplinar com outras áreas do conhecimento. Por outro lado, foi possível verificar que houve nestes anos um aprofundamento das reflexões teóricas e metodológicas no uso das fontes orais que transformaram o Brasil numa referência no que tange aos debates acerca desse tema. Apesar de suas limitações, este artigo revelou alguns dados que indicam a pujança do campo no Brasil e podem servir de base para o estabelecimento de novas estratégias para o desenvolvimento e expansão desta área de conhecimento em nosso país. Além disso, este artigo pretendeu incitar outros colegas a desenvolver reflexões sobre a História da História Oral no Brasil.

\section{Referências bibliográficas}

D’ARAÚJO, Maria Celina. Como a História Oral chegou ao Brasil. Entrevista com Aspásia Camargo a Maria Celina D’Araújo. História Oral, v. 2, 1999, p. 167-79.

FERREIRA, Marieta de M. Desafios e dilemas da história oral nos anos 90: o caso do Brasil. História Oral, v. 1, 1998, p. 19-30.

História oral: um inventário das diferenças. In: (coord.) Entre-vistas: abordagens e usos da história oral. Rio de Janeiro: Editora da Fundação Getúlio Vargas, 1994.

GRELE, Ronald J. The View from Where We Stand: Oral History and Expanded Horizons. História Oral, v. 8, n. 2, 2005, p. 77-85.

JOUTARD, Philippe. Ces voix qui nous viennent du passé, Paris: Hachette (Coll. "Le temps \& les hommes"), 1983. 
MONTENEGRO, Antonio Torres. Entrevista. Usos da Memória. In: Revista Saecolum do Programa de Pós-Graduação em História da UFPB, v. 8. João Pessoa: Editora da UFPB, 2008, p. 8-32.

Rachar as palavras. Ou uma história a contrapelo. In: Estudos Ibero-Americanos. V. XXXII. Porto Alegre: EDIPUCRS, 2006, p. 37- 62.

PEREIRA NETO, André. A História Oral da criação do Conselho de Medicina: notas sobre uma experiência. In: Von Simson (org.) Os Desafios Contemporâneos da História Oral. Campinas: Unicamp. p.137-48.

PERKS, Robert. Into the Mainstream: The Challenge of Oral History in Britain in the $21^{\text {st }}$. Century. História Oral, v. 6, 2003, p. 55-68.

SMITH, Richard C. Oral History at the University of California, Berkeley. História Oral, v. 6 , 2003, p. 45-54

Resumo: Este artigo oferece uma análise preliminar da produção acadêmica brasileira de História Oral entre 1998 e 2008 utilizando os artigos publicados na revista da Associação Brasileira de História Oral e os resumos das comunicações apresentadas nos encontros nacionais desta associação. Inicialmente é desenvolvida uma análise histórica e historiográfica do contexto em que emergiu a História Oral e sua associação. Em seguida são apresentados os resultados da pesquisa ressaltando o perfil dos autores e dos temas abordados. Ele revela a força da História Oral em nosso país e pode ser útil para o estabelecimento de estratégias para sua expansão.

Palavras-chave: História Oral; historiografia brasileira; Associação Brasileira de História Oral.

Oral History in Brazil: an analysis of recent production (1998/2008)

Abstract: This article provides a preliminary analysis of the Oral History academic output in Brazil between 1998 and 2008 by making use of articles published in the journal of the Brazilian Oral History Association and abstracts of communications presented in that association's national meetings. Initially a historical and historiographical analysis of the context in which Oral History and its association emerged is carried out. Then the results of the research are presented, highlighting the profile of the authors and themes addressed. It shows the strength of Oral History in our country and it may prove useful for the establishment of strategies for its expansion.

Keywords: Oral History; Brazilian historiography; Brazilian Oral History Association. 